In The Evolution of Cognition, ed. L. Huber and C. Heyes, pp. 241-252, MIT Press, 2000.

\title{
THE PRIVATIZATION OF SENSATION
}

\author{
Nicholas Humphrey \\ Department of Psychology \\ New School for Social Research
}

\section{$\underline{\text { Abstract }}$}

It is the ambition of evolutionary psychology to explain how the basic features of human mental life came to be selected because of their contribution to biological survival. Counted among the most basic must be the subjective qualities of conscious sensory experience: the felt redness we experience on lo oking at a ripe tomato, the felt saltiness on tasting an anchovy, the felt pain on being pricked by a thorn. But, as many theorists acknowledge, with these qualia, the ambition of evolutionary psychology may have met its match. Everyone agrees that a trait can only contribute to an organism's biological survival in so far as it operates in the public domain. Yet almost everyone also agrees that the subjective quality of sensory experience is (at least for all practical purposes) private and without external influence. Then, maybe we must either concede that the subjective quality of sensations cannot after all have been determined by selection (even if this is theoretically depressing) or else demonstrate that the quality of sensations is not as private as it seems to be (even if this is intuitively unconvincing). No. I believe neither of these solutions to the puzzle is in fact the right one. I argue instead that the truth is that the quality of sensations has indeed been shaped by selection in the past, despite the fact that it is today effectively private. And this situation has come about as a result of a remarkable evolutionary progression, whereby the primitive activity of sensing slowly became 
"privatized" - that is to say, removed from the domain of overt public behavior and transformed into a mental activity that is now, in humans, largely if not exclusively internal to the subject's mind.

D.H. Lawrence, the novelist, once remarked that if anyone presumes to ask why the midday sky is blue rather than red, we should not even attempt to give a scientific answer but should simply reply: "Because it is." And if anyone were to go still further, and to ask why his own conscious sensation when he looks at the midday sky is characterized by blue qualia rather than red qualia, I've no doubt that Lawrence if he were still around - along with several contemporary philosophers of mind would be just as adamant that the last place we should look for enlightenment is science.

But this is not my view. The poet William Empson wrote: "Critics are of two sorts: tho se who merely relieve themselves against the flower of beauty, and those, less continent, who afterwards scratch it up. I myself, I must confess, aspire to the second of these classes; unexplained beauty arouses an irritation in me" (Empson 1930). And equally, I'd say, unexplained subjective experience arouses an irritation in me. It is the irritation of someone who is an unabashed Darwinian: one who holds that the theory of evolution by natural selection has given us the licence to ask "why" questions about almost every aspect of the design of living nature, and, what's more, to expect that these "whys" will nearly always translate into scientifically accredited "wherefores".

Our default assumption, I believe, can and should be that living things are designed the way they are because this kind of design is - or has been in the past - biologically advantageo us. And this will be so across the whole of nature, even when we come to ask deep questions about the way the human mind works, and even when what's at issue are the central facts of consciousness.

Why is it like this to have red light fall on our eyes? Why like this to have a salt taste in our mouths? Why like this to hear a trumpet sounding in our ears? ... I think these questions, as much as any, deserve our best attempt to provide Darwinian answers: answers, that is, in terms of the biological function that is being - or has been - served.

There are two levels at which the questions can be put. First we should ask about the biological function of our having sensations at all. And, next, once we have an answer to this first 
question, we can proceed to the trickier question about the function of our sensations be ing of the special qualitative character they are.

No doubt the first will strike most people as the easy question, and only the second as the hard one. But I admit that even this first question may not be as easy as it seems. And, although I want to spend most of this paper discussing sensory quality, I realize I ought to begin at the beginning by asking: What do we gain, of biological importance, from having sensations at all?

To see why this seemingly easy question requires serious consideration and why the answer is not in fact self-evident, we have to take on board the element ary distinction between sensation and perception.

The remarkable fact that human beings - and presumably many other animals also — make use of their bodily senses in two quite different ways, was first brought to philosophical attention two hundred years ago by Thomas Reid. "The external senses," Reid wrote, "have a double province — to make us feel, and to make us perceive. They furnish us with a variety of sensations, some pleasant, others painful, and others indifferent; at the same time they give us a conception and an invincible belief of the existence of external objects. ... Sensation, taken by itself, implies neither the conception nor belief of any external object. It suppo ses a sentient being, and a certain manner in which that being is affected; but it supposes no more. Perception implies a conviction and belief of some thing ext ernal something different both from the mind that perceives, and the act of perception. Things so different in their nature ought to be distinguished" (Reid 1785, II, Ch. 17 \& 16).

For example, Reid said, we smell a rose, and two separate and parallel things happen: we both feel the sweet smell at our own nostrils and we perceive the external presence of a rose. Again, we hear a hooter blowing from the valley below: we both feel the booming sound at our own ears and we perceive the external presence of a ship down in the Firth. In general we can and usually do use the evidence of sensory stimulation both to provide "a subject-centred affect-laden representation of what's happening to me", and to provide "an objective, affectively neutral representation of what's happening out there" (Humphrey, 1992).

Yet, while Reid insisted so firmly on this difference, he never, it seems, thought it necessary to ask the question that so clearly follows on: Why do the senses have a double province? Do human 
beings really need both perception and sensation? If, as might well be argued - especially in the case of vision and hearing - what interests us in terms of our survival is not at all our personal relation to the stimulation at our body surface but only what this stimulation denotes about the outside world, why ever should we bother to represent "what is happening to me" as well as "what is happening out there"? Why should we not leave sensation out of it entirely and make do with perception on its own? Would not such insensate perception serve our biological need s perfectly well?

It is only in the last few years that psychologists have begun to face up to the genuine challenge of this question "why sensations?". And there is certainly no agreement yet on what the right Darwinian answer is. However there are now at least several possible answers in the offing. And I (Humphrey 1992), Anthony Marcel (1988) and Richard Gregory (1996) have all, in different ways, endorsed what is probably the strongest of these: namely, that sensations are required, in Gregory's felicitous wording, "to flag the present".

The idea here is that the main role of sensations is, in effect, to help keep perception honest. Both sensation and perception take sensory stimulation as their starting point: yet, while sensation then proceeds to represent the stimulation more or less as given, perception takes off in a much more complex and risky way. Perception has to combine the evidence of stimulation with contextual information, memory and rules so as to construct a hypothetical model of the external world as it exists independently of the observer. Yet the danger is that, if this kind of construction is allowed simply to run free, without being continually tied into present-tense reality, the perceiver may become lost in a world of hypotheticals and counterfactuals.

What the perceiver needs is the capacity to run so me kind of on-line reality check, testing his perceptual model for its currency and relevance and in part icular keeping tabs on where he himself now stands. And this, so the argument goes, is precisely where low level, unprocessed, sensation does in fact prove its value. As I summarized it earlier: "Sensation lends a here-ness and a now-ness and a me-ness to the experience of the world, of which pure perception in the absence of sensation is bereft" (Humphrey 1992, p.73). 
I think we should be reasonably happy with this answer. The need to flag the present provides at least one compelling reason why natural selection should have chosen sensate human beings over insensate ones.

But we should be under no illusion about how far this answer takes us with the larger project. For it must be obvious that even if it can explain why sensations exist at all, it goes no way to explaining why sensations exist in the particular qualitative form they do.

The difficulty is this. Suppose sensations have indeed evolved to flag the present. Then surely it hardly matters precisely how they flag the present. Nothing would seem to dictate that, for example, the sensation by which each of us represents the presence of red light at our eye must have the particular red quality it actually does have. Surely this function could have been performed equally well by a sensation of green quality or some other quality completely.

Indeed would not the same be true of any other functional role we attribute to sensations. For the fact is - isn't it? - that sensory quality is something private and ineffable, maybe of deep significance to each of us subjectively but of no consequence whatever to our standing in the outside world.

Certainly, there is a long philosophical tradition that makes exactly this claim. John Locke originated it with his thought experiment about the undetectable "inverted spectrum" (Locke 1690, II, Ch. 32). Imagine, said Locke, that "if by the different structure of our organs, it were so ordered, that the same object should produce in several men's minds different ideas at the same time; e.g. if the idea, that a violet produces in one man's mind by his eyes, were the same that a marigold produced in another man's, and vice versa." Then, Locke surmised, there's no reason to think this difference in inner structure and the resulting difference in the inner experience of the quality of colour would make any difference to outer behaviour. In fact, he claimed, the difference in inner experience "could never be known: because one man's mind could not pass into another man's body".

Ludwig Wittgenstein would later remark: "The assumption would thus be possible - though unverifiable - that one section of mankind has one sensation of red and another section another" (Wittgenstein 1958, I, 272). Indeed this unsett ling possibility became one of the chief reas ons why Wittgenstein himself decided to call a halt to any further talk about privately sensed qualities. And it is 
the reason, too, why other philosophers such as Daniel Dennett have been tempted to go even further, and to argue that sensory qualia have no objective reality whatever (Dennett 1988, although compare his more nuanced position of 1991).

Now, we need not go all the way with Wittgenstein or Dennett to realize that if even part of this argument about the privacy of qualia goes through, we may as well give up on our ambition to have a Darwinian explanation of them. For it must be obvious that nothing can possibly have evolved by natural selection unless it does in fact have some sort of major public effect - indeed unless it has a measurably positive influence on survival and reproduction. If, as common-sense let alone philos ophy suggests, sensory quality really is for all practical purpo ses private, selection simply could never have got a purchase on it.

It appears that we cannot have it both ways: Either as Darwinists we continue, against the odds, to try to explain sensory quality as a product of selection, or we grudgingly accept the idea that sensations are just as private as they seem to be.

So, what is to be done? Which of the se two strongly motivated positions must we give up?

I believe the answer is that actually we need not give up either. We can in fact hold both to the idea that sensory quality is private, and to the idea that it has been shaped by selection, provided we recognize that these two things have not been true at the same time: that, in the course of evolution, the privacy came only after the selection had occurred.

Here, in short, is the case that I would make. It may be true that the activity of sensing is today largely hidden from public view, and that the particular quality of sensations is not essential to the function they perform. It may be true, for example, that my sensation of red is directly known only to me, and that its particular redness is irrelevant to how it does its job. Yet, it was not always so. In the evolutionary past the activity of sensing was a much more open one, and its every aspect mattered to survival. In the past my ancestors evolved to feel red this way because feeling it this way gave them a real biological advantage.

Now, in case this so unds like a highly peculiar way of looking at history, I should stress that it would not be so unusual for evolution to have worked like this. Again and again in other areas of 
biology it turns out that, as the function of an organ or behaviour has shifted over evolutionary time, obsolete aspects of the original design have in fact carried on down more or less unchanged.

For a simple example, consider the composition of our own blood. When our fish-ancestors were evolving 400 million years ago in the Devonian seas, it was essential that the salt composition of their blood should closely resemble the external sea-water, so that they would not lose water by osmosis across their gills. Once our ancestors moved on to the land, however, and started breathing air, this particular feature of blood was no longer of critical importance. Nevertheless, since other aspects of vertebrate physiology had developed to fit in with it and any change would have been at least temporarily disadvantageous, well was left alone. The result is that human blood is still today more or less interchangeable with sea water.

This tendency towards what can be called "stylistic inertia" is evident at every level of evolution, not only in nature but in culture too. Clear examples occur in the development of language, manners, dress, and architectural design (as has been beautifully documented by Philip Steadman, 1979). But I would say that as nice a case as any is provided by the history of clocks and how their hands move.

Modern clocks have of course evolved from sundials. And in the Northern hemisphere, where clocks began, the shadow of the sundial's vane moves round the dial in the "sunwise" direction which we now call "clockwise". Once sundials came to be replaced by clockw ork mechanisms with moving hands, however, the reason for representing time by sunwise motion immediately vanished.

Nevertheless, since by this stage people's habits of time-telling were already tho roughly ingrained, the result has been that nearly every clock on earth still does use sunwise motion.

But suppose now, for the sake of argument, we were to be faced with a modern clock, and, as inveterate Darwinians, we were to want to know why its hands move the way they do. As with sensations, there would be two levels at which the question could be posed.

If we were to ask about why the clock has hands at all, the answer would be relatively easy. Obviously the clock needs to have hands of some kind so as to have some way of representing the passage of time - just as we need to have sensations of some kind so as to have some way of representing stimulation at the body surface. 
But if we ask about why the hands move clockwise as they do, the answer would have to go much deeper. For clearly the job of representing time could in fact now adays be served equally well by rotationally-inverted movement - just as the job of representing sensory stimulation could nowadays be served equally well by quality-inverted sensations. In fact, as we've seen, this second question for the clock can only be answered by reference to ancestral history — just as I would argue for sensations.

When an analogy fits the case as well as this, I would say it cries out to be taken further. For it strongly suggest s there is some profounder basis for the resemblance than has at first appeared. And in this case I think that, surprisingly, we really have struck gold. For it seems we may be arriving with this clock analogy at the crucial idea we need to unlock the mystery of what sensations are and how they have evolved.

A clock tells time by acting in a certain way, namely by moving its hands. And this action has a certain style inherited from the past, a clockwise style, clockwisely.

The remarkable truth is, I believe, that a person also has sensations by acting in a certain way. And, yes, each sensory action also has its own inherited style - for ex ample a red style, redly.

I have no space here to explain the full reasoning behind this theory. But I can at least attempt to sketch in the main themes.

As Reid long ago recognized, sensations are not what people mostly think they are. Our language misleads us. We talk of "feeling" or "having" sensations - as if somehow sensations were the

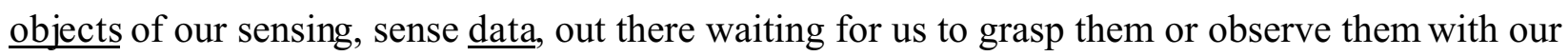
mind's eye. But analysis shows that this is a mistake. Sensations are no more the objects of sensing than, say, volitions are the objects of willing or intentions the objects of intending.

"The form of the expression, I feel pain," Reid wrote, "might seem to imply that the fee ling is something distinct from the pain felt; yet in reality, there is no distinction. As thinking a thought is an expres sion which could signify no more than thinking, so feeling a pain signifies no more than being pained. What we have said of pain is applicable to every other mere sensation" (Reid 1764, p. 112).

But I believe Reid got only part way to the truth here. For my own view (developed in detail in Humphrey 1992) is that the right expression is not so much 'being pained" as "paining". That's to 
say, sensing is not a passive state at all, but rather a form of active engagement with the stimulus occurring at the body surface. When, for example, I feel pain in my toe, or taste salt on my tongue, or equally when I have red sensation at my eye, I am in effect reaching out to the site of stimulation with a kind of evaluative response - a response appropriate to the stimulus and the body part affected. Indeed what I experience as my sensation of "what is happening to me" is based not on the incoming information as such but rather on the signals I myself am issuing to make the response happen.

This is how I feel about what's happening right now at my toe - I'm feeling painily about it.

This is how I feel about what's happening right now at this part of the field of my eye - I'm feeling redly about it.

Now, it is true that, today, these sensory responses are largely internal, covert and private. But, or so at least I want to argue, it was not always so. Rather, these responses began their evolutionary life as full-fledged bodily behaviours that were unambiguously in the public domain and, what is more, as behaviours with a real adaptive role.

If I try, as I shall do now, to sketch the evolutionary story in carto on form, it is because I want the general logic to come through rather than to attempt an accurate history. And I must trust you will be prepared to join me at this level.

So, let us return in imagination to the earliest of times and picture a primitive amoeba-like animal floating in the ancient seas.

This a nimal has a defining edge to it, a structural boundary - and this boundary is crucial, serving both to hold the animal's own substance in and the rest of the world out, and as the vital frontier across which essential exchanges of matter and energy and information can take place.

Now light falls on the animal, objects bump into it, pressure waves press against it, chemic als stick to it, and so on. No doubt some of these surface events are going to be a good thing for the animal, others bad. And in order for the animal to survive it must have evolved the ability to sort out the good from the bad and to respond differently to them - reacting to this stimulus with an ow! to that with an ouch! to this with a whowee!

Thus, when, say, salt arrives at its skin it detects it and makes a characteristic wriggle of activity - it wrigg les saltily. When red light falls on it, it makes a different kind of wriggle — it 
wriggles redly. Presumably these are adaptive responses, selected because they are appropriate to the animal's particular needs. Wriggling saltily has been selected as the best response to salt, while wriggling sugarly, for example, would be the best response to sugar. Wriggling redly has been selected as the best response to red light, while wriggling bluely would be the best response to blue light.

Still, as yet, these responses are nothing other than responses, and there is no reason to suppose that the animal is in any way mentally aware of what is happening. Lets imagine however that, as this animal's life becomes more complex, the time comes when it will be advantageous for it to have some kind of inner knowledge of what is affecting it: a mental representation of the sensory stimulation at the surface of its body and how it feels about it. Indeed one of the reasons it may need this kind of representation may be precisely the one we discussed earlier, namely to be able to flag the present.

Now, one way of developing this capacity for representing sensory stimulation might be to start over again with a completely fresh analysis of the incoming information from the sense organs. But, as it happens, this would be to miss a trick. For, the fact is that all the requisite details about the stimulation - where the stimulus is oc curring, what kind of stimulus it is, and how it should be dealt with - are already encoded in the command signals the animal is issuing when it makes the appropriate sensory response.

Hence, all the animal needs to do to sense "what's happening to me" is to pick up on these already-occurring command signals. To sense the presence of salt at a certain location on its skin, it need only monitor its own signals for wriggling saltily at that location, or equally to sense the presence of red light it need only monitor its signals for wriggling redly.

Thus the result is that sensations do indeed evolve at first as corollaries of the animal's public bodily activity. And since, in these early days, the form of this activity is still being maintained by natural selection, it follows that the form of the animal's mental representation — its sensory "experience" or proto-experience, if you like — is also going to be determined in all its aspects by selection. 
Yet, the story is of course by no means over. For, as this animal continues to develop and to change its lifestyle, the nature of the selection pressures is bound to alter. In particular, as the animal becomes more independent of its immediate environment, the making of sensory responses directly to the stimulus becomes of less and less relevance to its biological survival. In fact there comes a time when wriggling saltily or redly at the po int of stimulation no longer has any adaptive value at all.

Then, why doesn't the animal simply give up on this kind of local responding altogether? The reason is that, even though it may no longer have any use for the sensory responses as such, it has by this time become heavily dependent on the secondary representational functions that these responses have acquired. And since the way it has been getting the se representations in the past has been by monitoring its own command signals for sensory respons es, it clearly cannot afford to stop issuing the se command signals entirely.

So, the situation now is this. In order to be able to represent "what's happening to me", the animal must in fact continue to issue commands such as would produce an appropriate response at the right place on the bo dy if they were to carry through into bodily behaviour. But, given that the behaviour is no longer wanted, it may be better if these commands remain virtual or as-if commands — in other words, commands which, while retaining their original intentional propert ies, do not in fact have any real effects.

And the upshot is - or so I argue - that, over evolutionary time, there is a slow but remarkable change. What happens is that the whole sensory activity gets "privatized": the command signals for sensory responses get short-circuited before they reach the body surface, so that instead of reaching all the way out to the site of stimulation they now reach only to points closer and closer in on the incoming sensory nerve, until eventually the whole process becomes closed off from the outside world in an internal loop within the brain.

Now once this happens the role of natural selection must of course sharply diminish. The sensory responses have lost all their original biological importance and have in fact disappeared from view. Therefore selection is no longer involved in determining the form of these responses and a fortiori it can no longer be involved in determining the quality of the representations based on them. The conclusion is that sensory experience as such has become privatized. 


\section{Local response occurs at point of stimulation}

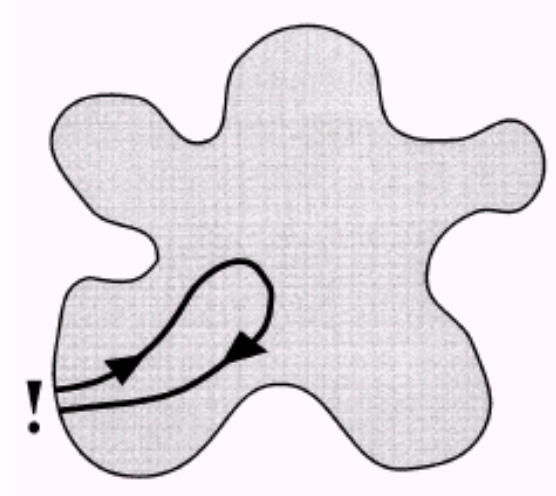

\section{Response becomes targeted on incoming sensory nerve}

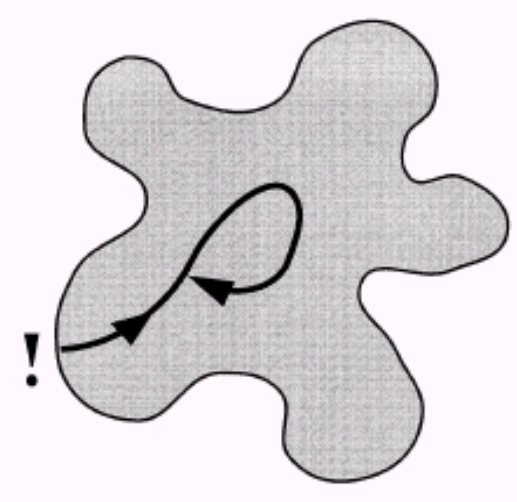

\section{Response becomes "privatized" within the brain}

Note well, however, that this privacy has come about only at the very end, after natural selection has done its work to shape the sensory landscape. In fact there is every reason to suppose that the forms of sensory responses and the corresponding experiences have already been more or less permanently fixed. And although, once selection becomes irrelevant, these forms may be liable to drift somewhat, they are likely always to reflect their evolutionary pedigree.

It is this pedigree that still colours private sensory experience right down to the pres ent day. If, I today feel the sensation red this way — as I know very well that I do — it is because I am descended from distant ancestors who were selected to feel it this same way long ago.

Here we are, then, with the solution that I promised. We can have it both ways. We can both make good on our ambition, as Darwinists, to explain sensory quality as a product of selection, and we can accept the common-sense idea that sensations are as private as they seem to be - provided we do indeed recognize that these two things have not been true at the same time. But the rewards of this Darwinian approach are I believe greater still. For there remains to be told the story of how, after 
the privatization of sensory responses has taken place and the command signals have begun to loop back on themselves within the brain, there are likely to be dramatic consequences for sensory phenomenology. In particular, how the activity of sensing is destined to become self-sustaining and partly self-creating, so that sensory experiences get lifted into a time dimension of their own - into what I have called the "thick time" of the subjective present (Humphrey 1992, 1995). What is more, how the establishment of this time-loop is the key to the thing we value most about sensations: the fact that not only do they have quality but that this qua lity comes across to us in the very special, selfintimating way, that we call the what it's like of consciousness.

When did this transformation finally occur? Euan Macphail (Chapter ?, this volume) argues that conscious sensations require the prior existence of a self. The philosopher Gottlob Frege made a similar claim, saying "An experience is impossible without an experient. The inner world presupposes the person whose inner world it is" (Frege 1967, p. 27). I agree with both these writers about the requirement that sensations have a self whom they belong to. But I think MacPhail, in particular, goes much too far with his insistence that such a self can only emerge with language. My own view is that self-representations arise through action, and that the "feeling self" may actually be created by those very sensory activities that make up its experience.

This is however another story for another time. I will simply remark here, with Rudyard Kipling, contra Lawrence, that "Them that asks no questions isn't told a lie" — and no truths either.

Note. An earlier version of this chapter appeared in "Towards a Science of Consciousness III. The Third Tucson Discussions and Debates" (Hameroff, S, Kaszniak, A, Chalmers, D, eds), Cambridge MA: MIT Press.

\section{REFERENCES}

Dennett, DC (1988) Quining Qualia. In Consciousness in Contemporary Science (Marcel, AJ, Bisiach, E, eds), pp 42-77. Oxford: Clarendon Press. 
Dennett, DC (1991) Consciousness Explained. New Y ork: Little Brown.

Empson, W (1930) Seven Types of Ambiguity. London: Chatto \& Windus.

Gregory, RL (1996) What do qualia do? Perception 25: 377-8.

Humphrey, N (1992) A History of the Mind. London: Chatto \& Windus.

Humphrey, N (1995) The thick moment. In The Third Culture (Brockman, J, ed) pp 198-208. New York: Simon \& Schuster.

Locke, J (1690 / 1975) An Essay Concerning Human Understanding (Nidditch, P, ed). Oxford: Clarendon Press.

Marcel, AJ (1988) Phenomenal experience and functionalism. In Consciousness in Contemporary Science (Marcel, AJ, Bisiach, E, eds) pp 121-158. Oxford: Clarendon Press.

Frege, G (1967) The Thought: a Logical Inquiry. In Philosophical Logic (Strawson, PF, ed). Oxford: Oxford University Press.

Reid, T (1764 / 1813) An Inquiry into the Human Mind (Stewart, D, ed). Charlestown: Samuel Etheridge.

Reid, T (1785 / 1813) Essays on the Intellectual Powers of Man (Stew art, D, ed). Charlestown: Samuel Etheridge.

Steadman, P (1979) The Evolution of Designs. Cambridge: Cambridge University Press. 
Witt gens tein, L (1958) Philos ophical Investigations (Anscombe, GEM, trans). Oxford: Blackwell. 